\title{
Spacer Thickness-Dependent Electron Transport Performance of Titanium Dioxide Thick Film for Dye-Sensitized Solar Cells
}

\author{
Reda E. El-Shater, ${ }^{1,2}$ Mohamed M. Abdel-Galeil, ${ }^{1,3}$ Go Kawamura, ${ }^{1}$ and Atsunori Matsuda ${ }^{1}$ \\ ${ }^{1}$ Department of Electrical and Electronic Information Engineering, Toyohashi University of Technology, 1-1 Hibarigaoka, \\ Tempaku-cho, Toyohashi, Aichi 441-8580, Japan \\ ${ }^{2}$ Physics Department, Faculty of Science, Tanta University, Tanta 31527, Egypt \\ ${ }^{3}$ Analytical \& Electrochemistry Research Unit, Chemistry Department, Faculty of Science, Tanta University, Tanta 31527, Egypt
}

Correspondence should be addressed to Atsunori Matsuda; matsuda@ee.tut.ac.jp

Received 23 April 2015; Revised 15 July 2015; Accepted 29 July 2015

Academic Editor: Chuanbao Cao

Copyright ( $) 2015$ Reda E. El-Shater et al. This is an open access article distributed under the Creative Commons Attribution License, which permits unrestricted use, distribution, and reproduction in any medium, provided the original work is properly cited.

\begin{abstract}
A titanium dioxide (P25) film was deposited by cast coating as conductive photoelectrode and subsequently immersed in dye solution (N719) to fabricate the photoanode of dye-sensitized solar cells (DSSCs). A plastic spacer was used as a separation and sealant layer between the photoanode and the counter electrode. The effect of the thickness of this spacer on the transfer of electrons in the liquid electrolyte of the DSSCs was studied by means of both IV curves and electrochemical impedance. Using a spacer thickness range of $20 \mu \mathrm{m}$ to $50 \mu \mathrm{m}$, efficiency ranges from $3.73 \%$ to $7.22 \%$. The highest efficiency of $7.22 \%$ was obtained with an optimal spacer thickness of $40 \mu \mathrm{m}$.
\end{abstract}

\section{Introduction}

O’Regan and Grätzel discovered the third generation of solar cells 20 years ago; the cells were so-called dye-sensitized solar cells (DSSCs) which showed photoelectric energy conversion rate reaching 7.1\%. The simple structure and low-cost fabrication of DSSCs have attracted a large number of researchers in an effort to improve its efficiency and stability $[1,2]$.

The structure of DSSC is as follows: photoanode made of a glass sheet treated with a transparent conductive layer, typically indium tin oxide (ITO) or fluorine-doped tin oxide (FTO). This conducting glass sheet is coated with a porous oxide layer (typically $\mathrm{TiO}_{2}$ ) to aid in electron transfer and a monolayer charge-transfer dye covalently bonded to the surface of the porous oxide layer to enhance light absorption. A cathode (counter electrode) is made of a typically ITO or FTO glass substrate, as a conducting medium for the electrons generated at the photoanode, sputtered with a catalyst (typically platinum) to catalyze a redox couple electrolyte (typically iodide/iodine). The two electrodes are combined, separated by a hollow plastic spacer. The space between the two electrodes is filled with an electrolyte, containing a redox mediator in an organic solvent, effecting dye regenerating [3]. Thus, the amount of the electrolyte is proportional to the space between the two electrodes and hence the thickness of the spacer. When the DSSC device is exposed to sunlight, the dye absorbs light and gets excited, injecting the excited electrons into the conduction band of the porous $\mathrm{TiO}_{2}$; the electrons are transported to the conducting ITO or FTO glass layer which transports them, through a load to the counter electrode. At the counter electrode, the electrons are transferred to the electrolyte, which serves as a hole conducting medium in the reaction, $3 \mathrm{I}^{-}+2 \mathrm{~h}^{+}=\mathrm{I}_{3}^{-}$. This is catalyzed by the platinum. At the electrolyte-dye interaction face, the dye is regenerated by the reaction, $2 \mathrm{I}^{-}+$Dye $^{+} \rightarrow \mathrm{I}_{2}^{-\bullet}+$ Dye, where $\mathrm{I}_{2}^{-\bullet}$ is diiodide radical. The triiodide is regenerated from this reaction by the disproportionation reaction of the diiodide, $2 \mathrm{I}_{2}{ }^{-} \rightarrow \mathrm{I}^{-}+$ $\mathrm{I}_{3}{ }^{-}$. During these processes, electrons in the conduction band of semiconductor may be recombined with the dye sensitizer or electron acceptor species in the electrolyte solution. The electron collection efficiency in DSSC is determined by the competition between transport of electrons within the porous semiconductor on one hand and recombination of electrons with $\mathrm{I}_{3}{ }^{-}$ions in the electrolyte on the other hand [4]. 
The overall performance of DSSC can be evaluated in terms of cell efficiency $(\eta)$ and fill factor (FF) expressed as

$$
\begin{aligned}
\mathrm{FF} & =\frac{V_{\mathrm{max}} J_{\mathrm{max}}}{V_{\mathrm{oc}} J_{\mathrm{sc}}} \\
\eta & =\frac{V_{\mathrm{oc}} J_{\mathrm{sc}}}{P_{\mathrm{in}}} \mathrm{FF} \times 100 \%,
\end{aligned}
$$

where $J_{s c}$ is the short-circuit current density $\left(\mathrm{mA} / \mathrm{cm}^{2}\right)$, $V_{\text {oc }}$ the open-circuit voltage $(V)$, and $P_{\text {in }}$ the incident light power. $J_{\max }$ and $V_{\max }$ correspond to current and voltage values, respectively, where the maximum power output is given in the $J-V$ curve. The open-circuit voltage varies with the iodide concentration because the recombination reaction occurs between the electrons on the conduction band of $\mathrm{TiO}_{2}$ and triiodide $\left(\mathrm{I}_{3}{ }^{-}\right)$. A variety of similar circuits have been studied and data obtained by electrochemical impedance spectroscopy shows that FF can be optimized by minimizing internal series resistance [3].

The most efficient DSSCs are based on a mesoporous nanocrystalline $\mathrm{TiO}_{2}$ film which serves as a substrate for both the dye and the electron conductor. This provides not only large surface area for the adsorption of dyes for light harvesting, but also a network for electron transport to the FTO glass substrate and subsequently to the external circuit. Thus, the different parameters of the $\mathrm{TiO}_{2}$ photoanode, such as particle size, thickness, and the surface area, play important roles in the performance of DSSC [4]. A lot of studies have been performed to enhance or arrive at optimum efficiency of DSSC depending on the semiconductor active layer [5-12], the type of dye $[13,14]$, the composition and concentration of electrolyte $[13,15,16]$, and the type and thickness of counter electrode [17-21]. Wang et al. have used submicron $\mathrm{SiO}_{2} / \mathrm{TiO}_{2}$ core/shell particles which scatter light in the dyesensitized solar cells and the power conversion efficiency of dye-sensitized solar cells was increased by about $50 \%$ after the introduction of light scattering $\mathrm{SiO}_{2} / \mathrm{TiO}_{2}$ core/shell particles in the photoanode [5].

Chou et al. have investigated the applicability of a hybrid $\mathrm{TiO}_{2}$ electrode by introducing microcrystalline $\mathrm{TiO}_{2}$ particles as light scattering layer in the working electrode. They have found optimum conditions to arrive at beast power conversion efficiency of the DSSC depending on the structure of hybrid $\mathrm{TiO}_{2}$ electrode. The microcrystalline $\mathrm{TiO}_{2}$ particles improved the DSSC of working electrode consisting of commercial $\mathrm{TiO}_{2}-\mathrm{P} 25$ from $5.16 \%$ without scattering particles into $7.02 \%$, with optimum composite structure of $50 \% \mathrm{TiO}_{2}$ particles (P-25) and $50 \% \mathrm{TiO}_{2}$ scattering particles with an average size of 268.7 [6]. Kang et al. have modified a $\mathrm{TiO}_{2}$ film by adding light scattering particles and applied it to an anode electrode in solid state dye-sensitized solar cells (DSSCs). The $\mathrm{TiO}_{2}$ films with 10 wt $\%$ (versus $\mathrm{TiO}_{2}$ weight) light scattering particles showed enhanced performance (28\%), compared with nanocrystalline $\mathrm{TiO}_{2}$ films [7].

Choi et al. have studied the surface of light scattering $\mathrm{TiO}_{2}$ particles in the dye-sensitized solar cell (DSSC). The $\mathrm{TiO}_{2}$ particles were dual-coated with $\mathrm{Al}_{2} \mathrm{O}_{3}$ and $\mathrm{SiO}_{2}$ nanoparticles. It was revealed that the dual-coated light scattering $\mathrm{TiO}_{2}$ particles lead to an increase in short-circuit photocurrent of
DSSC device, resulting in an increase in energy conversion efficiency. This seems to be due to the increase of the light scattering by a combination of the light scattering $\mathrm{TiO}_{2}$ particles and the oxide nanoparticles such as $\mathrm{Al}_{2} \mathrm{O}_{3}$ and $\mathrm{SiO}_{2}$ [8].

Lai et al. have prepared submicron-sized functional $\mathrm{YVO}_{4}: \mathrm{Eu}^{3+}, \mathrm{Bi}^{3+} @ \mathrm{SiO}_{2}$ core-shell particles using a hydrothermal method. These particles were embedded in the photoanodes of dye-sensitized solar cells. The embedded $\mathrm{YVO}_{4}: \mathrm{Eu}^{3+}, \mathrm{Bi}^{3+} @ \mathrm{SiO}_{2}$ particles not only enhanced light scattering within the photoanode, but were also able to downconvert ultraviolet light to visible light. The enhanced light scattering can greatly extend the light traveling distance within the photoanode, while the ultravioletvisible downconversion property can effectively improve the utilization efficiency of short wavelength photons by the dye-sensitized solar cells. The embedded submicronsized $\mathrm{YVO}_{4}: \mathrm{Eu}^{3+}, \mathrm{Bi}^{3+} @ \mathrm{SiO}_{2}$ particles increased the power conversion efficiency of dye-sensitized solar cell by about $64 \%$ from $3.6 \%$ to $5.9 \%$ [9]. Lee et al. have fabricated nanoporous $\mathrm{TiO}_{2}$ nanotubes (TNTs) modified by $\mathrm{TiCl}_{4}$. The $\mathrm{TiCl}_{4}$ treatment on TNTs film enhanced short-circuits current density $\left(J_{\text {sc }}\right)$. But also aluminum oxide $\left(\mathrm{Al}_{2} \mathrm{O}_{3}\right)$ posttreatment enhanced open-circuit voltage $\left(V_{\mathrm{oc}}\right)$. As a result, $\mathrm{Al}_{2} \mathrm{O}_{3}$ posttreatment on TNTs film realized conversion efficiency of $8.65 \%$, which is $7 \%$ higher than only $\mathrm{TiCl}_{4}$ treatment [11].

Zhu et al. have fabricated dye-sensitized solar cells (DSSCs) based on double-layered films of $\mathrm{TiO}_{2}$ nanospheres and $\mathrm{TiO}_{2}$ nanorod arrays (NRAs). $\mathrm{TiO}_{2}$ nanospheres, including $\mathrm{TiO}_{2}$ hollow spheres (HSs) and $\mathrm{TiO}_{2}$ solid spheres (SSs), were served as light scattering layers on $\mathrm{TiO}_{2}$ NRAs as composite photoanodes. Owing to the synergic effects of the $\mathrm{TiO}_{2}$ HSs (SSs) and NRAs, including large specific surface area of HSs (SSs) as light scattering layer for effective dye adsorption and harvesting light and rapid electron transport in onedimensional $\mathrm{TiO}_{2}$ NRAs, the optimal energy conversion efficiency of DSSCs with as-prepared double-layered films as nanocomposite photoanode $(5.40 \%)$ was far higher than the ones using single-layered NRAs films (1.56\%) [10]. Zhao et al. dye-sensitized solar cells (DSCs) based on different thickness of mesoporous $\mathrm{TiO}_{2}$ thin film electrodes were fabricated with dye $\mathrm{C106}$. The overall conversion efficiency $(\eta)$ was improved when the thickness of $\mathrm{TiO}_{2}$ film increased from $2.1 \mu \mathrm{m}$ to $9.8 \mu \mathrm{m}$, and obvious decreases of $J_{\text {sc }}$ and $\eta$ were found when the film thickness was further increased over $9.8 \mu \mathrm{m}$. The results showed that the density of states and recombination rate increased with the film thickness increasing. Furthermore, when the film thickness was in the range of $2.1-9.8 \mu \mathrm{m}$, the electron lifetime $\left(\tau_{n}\right)$, the electron diffusion coefficient $\left(d_{n}\right)$, and the electron diffusion length $\left(L_{n}\right)$ of devices increased, but these parameters decreased gradually with the further increased thickness of $\mathrm{TiO}_{2}$ film, which influenced the electronic transport performance of DSSCs [12].

Yella et al. have reported microscopic solar cells that incorporate a Co ${ }^{(\mathrm{II} / \mathrm{III})}$ tris(bipyridyl)-based redox electrolyte in conjunction with a custom synthesized donor- $\pi$-bridgeacceptor zinc porphyrin dye as sensitizer (designated YD2o-C8). The specific molecular design of YD2-o-C8 greatly retards the rate of interfacial back electron transfer from 
the conduction band of the nanocrystalline titanium dioxide film to the oxidized cobalt mediator, which enables attainment of strikingly high photovoltages approaching 1 volt. Because the YD2-o-C8 porphyrin harvests sunlight across the visible spectrum, large photocurrents are generated. Cosensitization of YD2-o-C8 with another organic dye (Y123) further enhances the performance of the device, leading to a measured power conversion efficiency of $12.3 \%$ under simulated air mass 1.5 global sunlight [13].

Kim et al. have reported on synthetic strategy of organic dye to get high photovoltage. Phenothiazine (PTZ) moieties are incorporated between electron donating triphenylamine (D) and electron accepting cyanoacrylic acid (A) to enhance nonplanarity. Compared to one PTZ incorporation (DPTZ-A), hypsochromic shift in absorption is observed by incorporation of two PTZs (D-PTZ1- PTZ2-A). D-PTZ1PTZ2-A shows higher photovoltage $(0.804 \mathrm{~V})$ than D-PTZA $(0.781 \mathrm{~V})$, those which are even higher than that of the ruthenium-based N719-sensitized one (0.775 V). Little difference in electron transport rate is observed for PTZ derivatives and N719, while electron lifetime is increased in the order of D-PTZ1- PTZ2-A > D-PTZ-A > N719. Retardation of electron recombination is responsible for the high photovoltage, which is associated with bent conformation induced by PTZ spacer group [14].

The essential properties of a material to be used as counter electrode in a dye-sensitized solar cell are a low chargetransfer resistance and high exchange current densities for the reduction of the oxidized form of the charge mediator [17]. The best material that acts as a catalyst and provides high exchange current for this reaction is platinum. However, researchers tried to use a carbon counter electrode consisting of a low-cost carbon powder but the performance is low maybe due to much higher electrical resistance than Pt [18]. Anandan et al. have studied the possibility of replacing the more expensive $\mathrm{Pt}$ counter electrode by $\mathrm{p}-\mathrm{CuO}$ nanorod. The assembled $\mathrm{CuO}$ nanorods as cathode in dye-sensitized solar cells are able to achieve an energy conversion efficiency of $0.29 \%$ whereas for Pt counter electrode as cathode an energy conversion efficiency of $1.32 \%$ is obtained at the same illumination conditions. The large surface area, excellent stability, low production cost, and good electrical properties of $\mathrm{p}$ $\mathrm{CuO}$ nanorod are quite promising considering that further optimization of the photovoltaic performance is possible in the future [17].

The electrolyte is a key component of dye-sensitized solar cells (DSSCs). It functions as a charge carrier, collecting electrons at the cathode and transporting them back to the dye molecules. One important factor that needs to be considered, when using $\mathrm{I}^{-} / \mathrm{I}_{3}{ }^{-}$redox couple electrolyte, is its concentration. At low iodine concentration, it is difficult to maintain sufficient electrolyte conductivity and hence rapid redox reaction. On the other hand, when iodine concentration is too high, electron recombination at the $\mathrm{TiO}_{2}$ electrolyte interface deteriorates the performance of DSSCs and meanwhile the rate of light absorption by redox couple is increased $[22,23]$. The above factors are usually explored to prepare low-cost advanced materials for photovoltaic energy production and also study the mechanism of photovoltaic processes in this class of solar cells.

The above findings have been performed to understand the link between each component (dyes, electrolytes, and counter electrodes) and solar cell performance and could help in increasing the solar cell efficiency to the levels required for commercialization. But no one tries to study experimentally the effect of spacer thickness on cell performance. There is theoretical study point to the effect of spacer thickness and electrolyte amount on cell parameters [24]. In this study, we try to investigate the $I-V$ curves, EIS measurements, and their parameters to understand the role of spacer thickness in DSSC.

\section{Experimental Details}

2.1. Materials. All reagents were of commercial grade and were used without further purification. The commercial $\mathrm{TiO}_{2} \mathrm{P} 25$ powder was purchased from Wako (Japan). Ethylene glycol (EG) and citric acid (CA) were both purchased from Shin-Etsu (Japan). The deionized water used in this work was obtained by a water distillation apparatus (Toyo Seisakusho Kaisha, AQUARIUSPFD 23 ONA, Japan). FTO glass substrate $\left(10 \Omega \square^{-1}, 85 \%\right.$ transmittance) was purchased from Astellatech (Japan). Absolute ethanol (99.99\%) was obtained from Wako (Japan). Titanium isopropoxide (TTIP), acetylacetone (AcAc), iodine, 4-tert-butylpyridine (TBP), lithium iodide, acetonitrile, and the $\mathrm{Ru}$ dye [cisdi(thiocyanato)-bis(2,2-bipyridyl-4,4-dicarboxylate) ruthenium(II) (N719)] were purchased from Aldrich (Japan). The spacer was purchased from DuPont-Mitsui Polychemicals Co. Ltd., Japan.

2.2. Preparation of $\mathrm{TiO}_{2}$ Sols. A $\mathrm{TiO}_{2}$ sol was prepared according to the Legrand-Buscema method [25]. In brief, TTIP was dissolved in dry isopropanol and vigorously stirred at room temperature for $30 \mathrm{~min}$. Pure AcAc was added with a molar ratio of $1: 3$ and the mixture stirred for $1 \mathrm{~h}$. Finally glacial acetic acid was slowly added to the solution to initialize the hydrolysis via an esterification reaction which leads to the in situ production of water, which initiates the hydrolysis. The molar ratio of acetic acid : TTIP was $1: 5$.

2.3. Preparation of P25 Paste. The P25 paste was prepared by a ball-milling method at room temperature. 5.6 g of P25 powder was ball-milled with $13 \mathrm{~mL}$ of ethylene glycol for $24 \mathrm{~h}$, and then $12.6 \mathrm{~g}$ of citric acid was added and ball-milling continued for another $24 \mathrm{~h} \mathrm{[22].}$

2.4. Preparation of Photoanode and DSSCs. $\mathrm{TiO}_{2}$ thin films were coated on FTO substrates with $\mathrm{TiO}_{2}$ sols by a sol-gel dipcoating (KSV Instrument, Dip-Coater KSV-DC, Japan) using various withdrawing speeds (e.g., 1, 5, and $10 \mathrm{~mm} \mathrm{~min}^{-1}$ ). After withdrawing, the films were calcined in air at $450^{\circ} \mathrm{C}$ for 30 min using a heating rate of $10^{\circ} \mathrm{C} \mathrm{min}^{-1}$. The $\mathrm{P} 25$ paste was then coated onto the substrates by cast coating and sintered at $450^{\circ} \mathrm{C}$ for $30 \mathrm{~min}$. In order to maintain a relatively constant film thickness, a double-layer adhesive tape was used for 


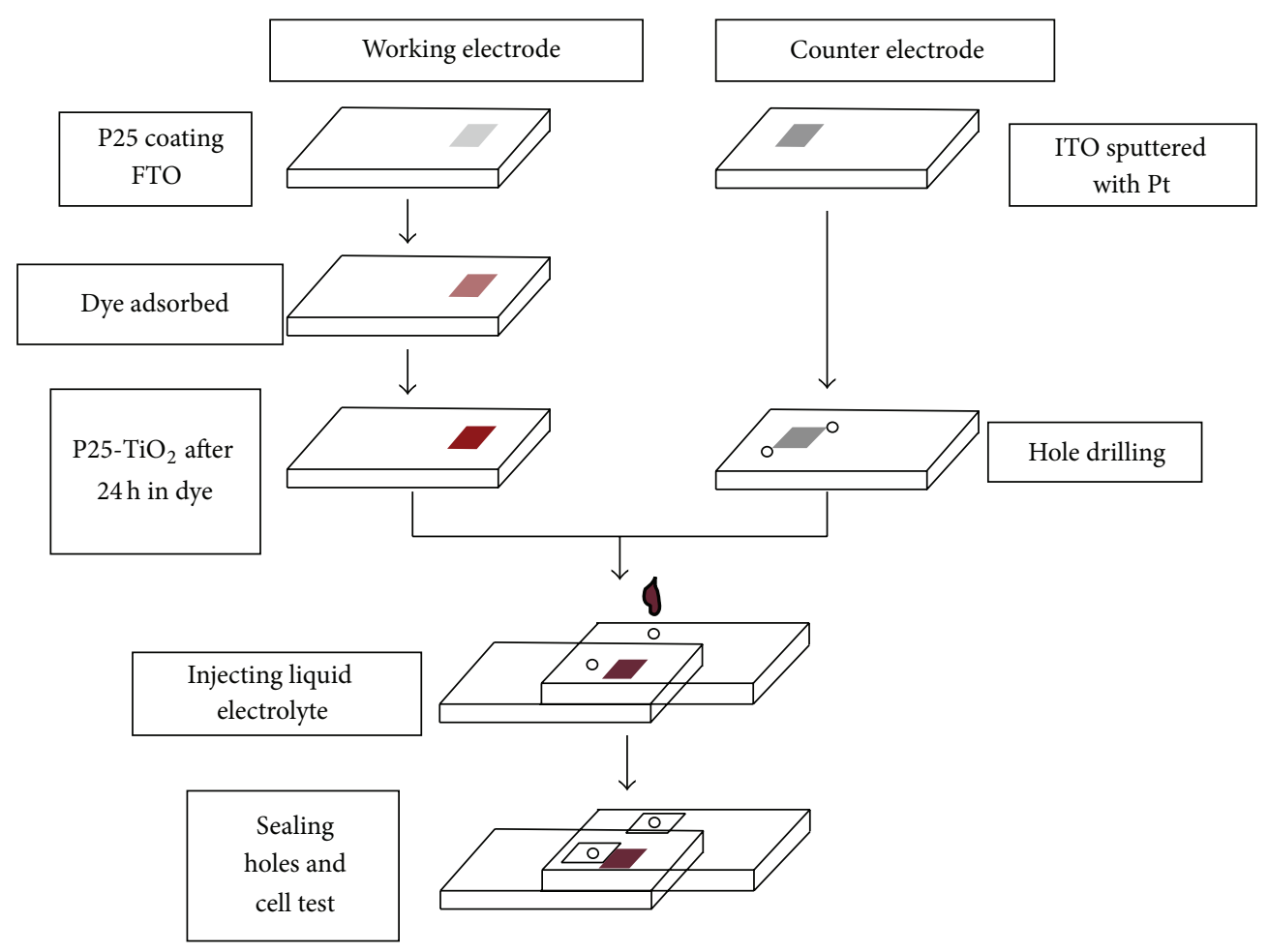

FIGURE 1: The experimental process for fabrication of the sealed solar cell.

the P25 paste casting on the FTO substrate, obtaining an average film thickness of $8 \mu \mathrm{m}$. The electrodes were then immersed in a $0.5 \mathrm{mM}$ ethanolic N-719 dye solution, for $24 \mathrm{~h}$ at room temperature, to allow complete dye adsorption. The counter electrode was made of a platinum-sputtered ITO glass substrate. The photoanode and the counter electrode were then separated by a hallow spacer and clamped together to form sandwich-type DSSC configuration [26]. An electrolyte composed of $0.1 \mathrm{M} \mathrm{LiI}, 0.05 \mathrm{M} \mathrm{I}_{2}, 0.6 \mathrm{M}$ 1-methyl3-propylimidazolium iodide, and $0.5 \mathrm{M}$ tert-Butyl pyridine in dried acetonitrile was injected into the space between the photoanode and the counter electrode. The experimental process of the sealed solar cell is shown in Figure 1.

2.5. Physical Measurements. The crystallinity, phase purity, and particle size of P25 were evaluated by powder X-ray diffraction (XRD) [Rigaku, Ultima IV diffractometer $(30 \mathrm{kV}$, $20 \mathrm{~mA}$, Japan) with $\mathrm{CuK} \alpha$ radiation $(\lambda=1.5406 \AA)]$. The thickness of $\mathrm{TiO}_{2}$ coated was evaluated by scanning electron microscope (SEM) (JEOL, S-4800, Japan). The sample was sputtered with a thin layer of platinum to avoid the charging effect. The thickness was measured using a cross section.

The current-voltage curves of the fabricated DSSCs were measured under illumination of AM 1.5 solar simulator, combined with a potentiostat/galvanostat (Bunkoukeiki, OTENTO-SUN, Japan).

Electrochemical impedance evaluation spectra of the DSSCs were obtained using a potentiostat electrochemical interface (Solartron Analytical, Model SI-1287, UK), which was connected to a frequency response analyzer (Solartron
Analytical, Model 1252A, UK), and operating in a twoelectrode mode, with a frequency range of $300 \mathrm{kHz}-0.10 \mathrm{~Hz}$ at an $\mathrm{AC}$ voltage of $10 \mathrm{mV}$. The frequency-dependent impedance was fitted using the Z-view software accompanied with Solartron equipment, with the aim of obtaining the space charge capacitance of $\mathrm{TiO}_{2}$-coated FTO electrodes.

\section{Results and Discussion}

3.1. Crystalline and Phase Purity of P25. XRD was used to investigate the consistent phase of the commercially available P25. XRD of P25 shows a strong peak intensity around $25.3^{\circ}$ (Figure 2(a)) and also peaks around $38^{\circ}, 48^{\circ}$, and $55^{\circ}$ which are characteristic of anatase-type $\mathrm{TiO}_{2}$ (JCPDS 211272). Weak peaks of rutile phase (35 and $44^{\circ}$ ) appeared after heat treatment at $450^{\circ} \mathrm{C}$ (Figure 2(b)). Moreover, it was found that the anatase peaks for the heat treated $\mathrm{TiO}_{2}$ sample were obviously sharper than those of the original P25 sample, demonstrating that the heat treatment process improved the crystallinity of $\mathrm{TiO}_{2}$. The XRD patterns also clearly reveal that the film does not contain other phases, such as brookite.

\subsection{The IV Curves of DSSC}

3.2.1. Optimization of P25 Layer Thickness. Figures 3(a), 3(b), and 3(c) represent the three different thicknesses of P25 samples prepared with thicknesses of 8,10 , and $12 \mu \mathrm{m}$, respectively. Figure 3(d) shows the $I-V$ characteristics of DSSCs fabricated using these samples. The detailed photovoltaic parameters such as $\eta, J_{\mathrm{sc}}, V_{\mathrm{oc}}$, and FF are registered in Table 1. 
TABLE 1: $I-V$ parameters of DSSCs with different thicknesses of P25 layer.

\begin{tabular}{lccc}
\hline P25 thickness $(\mu \mathrm{m})$ & 8 & 10 & 12 \\
\hline$J_{\text {sc }}\left(\mathrm{mA} \mathrm{cm}^{-2}\right)$ & 14.9 & 12.0 & 7.3 \\
$V_{\text {oc }}(\mathrm{V})$ & 0.81 & 0.80 & 0.73 \\
FF & 0.36 & 0.37 & 0.51 \\
$\eta \%$ & $4.2 \pm 0.09$ & $3.8 \pm 0.03$ & $2.7 \pm 0.11$ \\
\hline
\end{tabular}

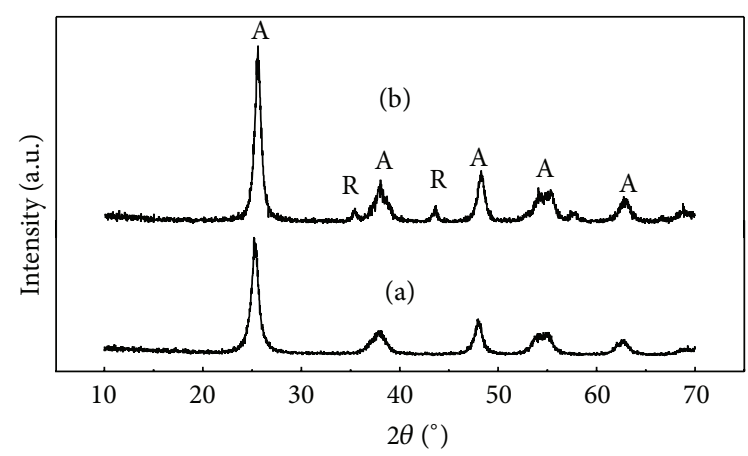

A: anatase

$\mathrm{R}$ : rutile

Figure 2: XRD patterns of commercially $\mathrm{TiO}_{2}$ P25: before (a) and after (b) heating at $450^{\circ} \mathrm{C}$.

With increasing P25 layer thickness, FF increased and $V_{\text {oc }}$ decreased. This would represent that the generation rate of free electrons increased, but at the same time recombination rate also increased. Thus, there was a competition between electron generation and recombination. Increasing the photoanode thicknesses caused decrease in the overall photovoltaic parameters values and hence decreases in the efficiency from $4.2 \%$ at $8 \mu \mathrm{m}$ to $2.7 \%$ at $12 \mu \mathrm{m}$. Thus, the best photoanode thickness of $8 \mu \mathrm{m}$ was obtained among these samples.

3.2.2. Optimization of Spacer Thickness. Figure 4 shows the $I$ $V$ characteristics for the DSSCs fabricated with two different amounts of electrolyte. The detailed photovoltaic parameters are shown in Table 2 and showed that when the amount of electrolyte decreased by around $50 \%$, the photovoltaic parameters decreased, but the fill factor increased. The reason for decreases of short-circuits current and open-circuit voltage would be that inadequate amount of injected electrolyte caused fewer amounts of liberated electrons and fewer amounts of electrons to accumulate at the photoanode. Then, we investigated the detailed effects of electrolyte amount on DSSC performance by changing the spacer thicknesses.

Changing the spacer thicknesses has been obtained by adding multilayers of spacer (each layer has a thickness of $10 \mu \mathrm{m}$ ) on the photoelectrode. Photocurrent-voltage characteristics of the corresponding DSSCs are shown in Figure 5, and the detailed photovoltaic parameters are summarized in Table 3. The convergence of photocurrent-voltage curves at short-circuit and open-circuit points indicates that the two vital parameters, $V_{\mathrm{oc}}$ and $J_{\mathrm{sc}}$, are independent of spacer
TABLE 2: $I-V$ parameters of DSSCs with different amounts of electrolyte.

\begin{tabular}{lcc}
\hline Electrolyte amount $(\mathrm{mL})$ & $6 \times 10^{-3}$ & $3 \times 10^{-3}$ \\
\hline$J_{\mathrm{sc}}\left(\mathrm{mA} \mathrm{cm}^{-2}\right)$ & 14.5 & 9.5 \\
$V_{\mathrm{oc}}(\mathrm{V})$ & 0.804 & 0.801 \\
$\mathrm{FF}$ & 0.36 & 0.43 \\
$\eta \%$ & $4.2 \pm 0.09$ & $3.2 \pm 0.10$ \\
\hline
\end{tabular}

thicknesses. The efficiency increased from $2.47 \%$ at $10 \mu \mathrm{m}$ to $7.21 \%$ at $40 \mu \mathrm{m}$ and then decreased to $5.92 \%$ at $50 \mu \mathrm{m}$ spacer thickness. However, in the vicinity of maximum power, there was increasing optimal slope of the photocurrent-voltage curves with increasing spacer thickness; the optimum was $40 \mu \mathrm{m}$.

According to a model work publication [9], the efficiency of the DSSC depended on electrolyte layer thicknesses. For smaller spacer thicknesses, the amount of electrolyte was inadequate to produce maximum generation of free electrons which compensate the liberated electrons in Ru dye. On the other hand, for larger spacer thicknesses, there was abundant amount of electrolyte which produced equivalent amount of liberated electrons in dye but increased the path length of free electrons through electrolyte and therefore increased the recombination probability of free electrons in the bulk of electrolyte due to the Warburg resistance of the electrolyte.

3.3. Electrochemical Impedance Spectroscopy. Electrochemical impedance spectroscopy (EIS) is an effective method for measuring the current response to the application of an $\mathrm{AC}$ voltage as a function of the frequency [27]. To investigate the interfacial characteristics of the DSSCs, the EIS measurements were performed over the frequency range of $0.1 \mathrm{~Hz}$ to $300 \mathrm{kHz}$. The applied bias voltage was set to the open-circuit voltage $\left(V_{o c}\right)$ of the DSSCs, and AC amplitude of $5 \mathrm{mV}$ was applied [28]. The internal resistances of the DSSCs consist of the sum of the resistances from each of the elements in the solar cell. There are contributions from the working electrode, the counter electrode, and the material transport between the electrodes.

The series resistance, $R_{s}$, is from the conduction through the conducting glass at the working and counter electrodes of the cell, which is primarily related to the sheet resistance of FTO. The transfer impedance $\left(R_{f}\right.$ and $\left.C_{f}\right)$ should be due to the charge-transfer processes occurring at the dye/electrolyte interface and P25 particles (P25/dye/electrolyte interface); this resistance is due to the recombination during chargetransfer process between the semiconductor and the electrolyte. The transport impedance $R_{p}$ and $C_{p}$ represented the electron transport process inside the P25 layer, $R_{\mathrm{Pt}}$ and $C_{\mathrm{Pt}}$ are the charge-transfer impedance of the reduction of redox species $\left(\mathrm{I}_{3}{ }^{-}\right.$to $\left.\mathrm{I}^{-}\right)$at the counter electrode, and the diffusion impedance (Warburg) of $\mathrm{I}^{-} / \mathrm{I}_{3}{ }^{-}$should be in the electrolyte; redox species in electrolyte diffuse between the working and counter electrodes and give rise to a diffusion resistance, $W_{s}$. The impedance from the diffusion of ions (Warburg impedance) is mainly determined by the diffusion 
TABLE 3: I-V parameters of DSSCs with different spacer thicknesses.

\begin{tabular}{lccccc}
\hline Spacer thickness $(\mu \mathrm{m})$ & 10 & 20 & 30 & 40 & 50 \\
\hline$J_{\text {sc }}\left(\mathrm{mA} \mathrm{cm}^{-2}\right)$ & 6.0 & 8.0 & 13.56 & 18.4 & 0.76 \\
$V_{\text {oc }}(\mathrm{V})$ & 0.747 & 0.735 & 0.757 & 0.755 \\
FF & 0.55 & 0.63 & 0.56 & 0.51 & 0.41 \\
$\eta \%$ & $2.476 \pm 0.08$ & $3.73 \pm 0.152$ & $5.84 \pm 0.26$ & $7.21 \pm 0.25$ & $5.92 \pm 0.23$ \\
\hline
\end{tabular}

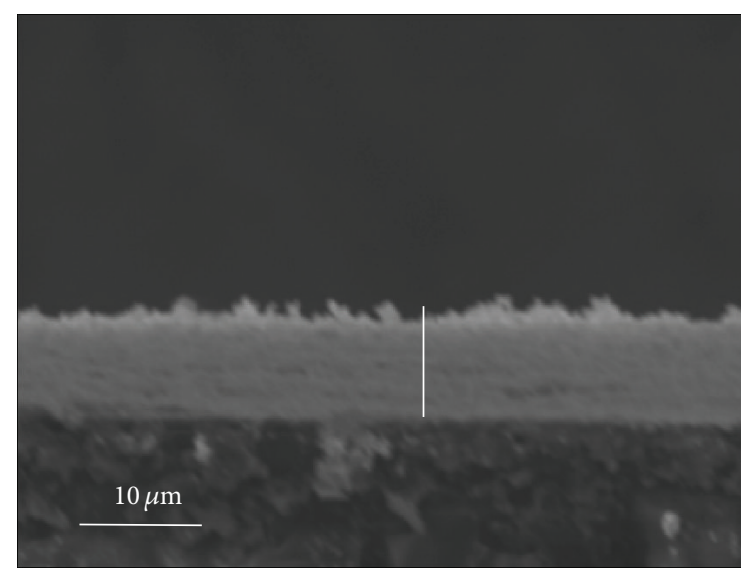

(a)

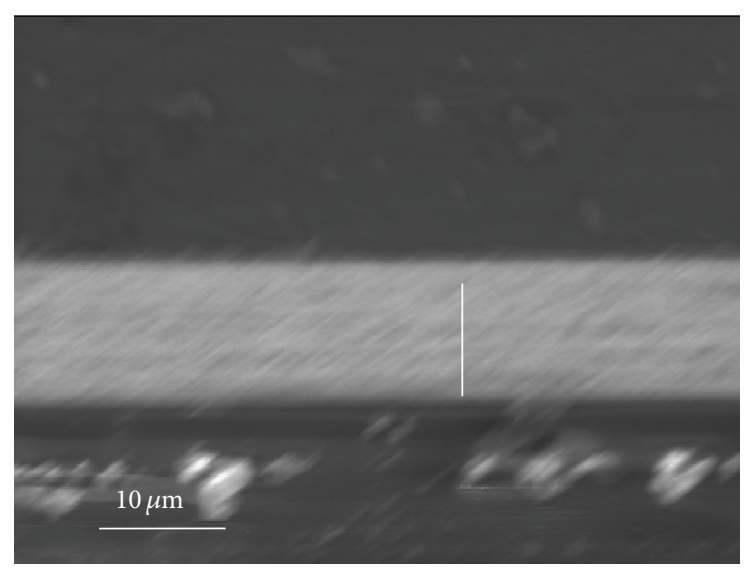

(c)

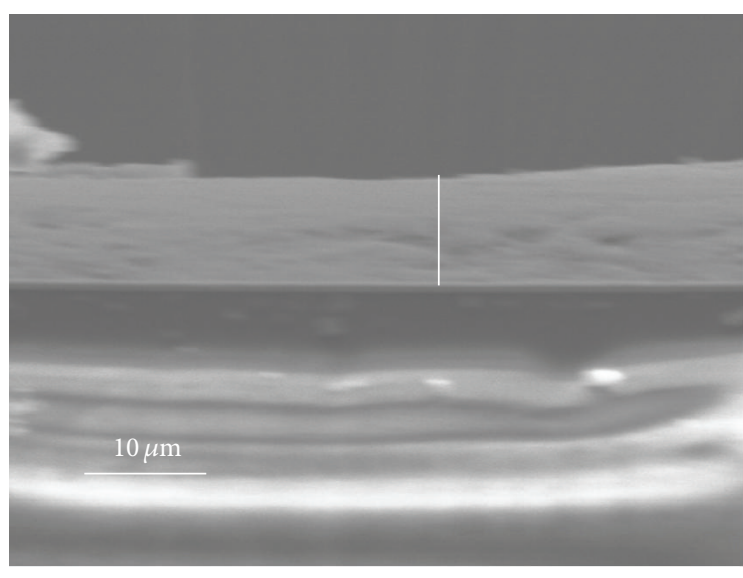

(b)

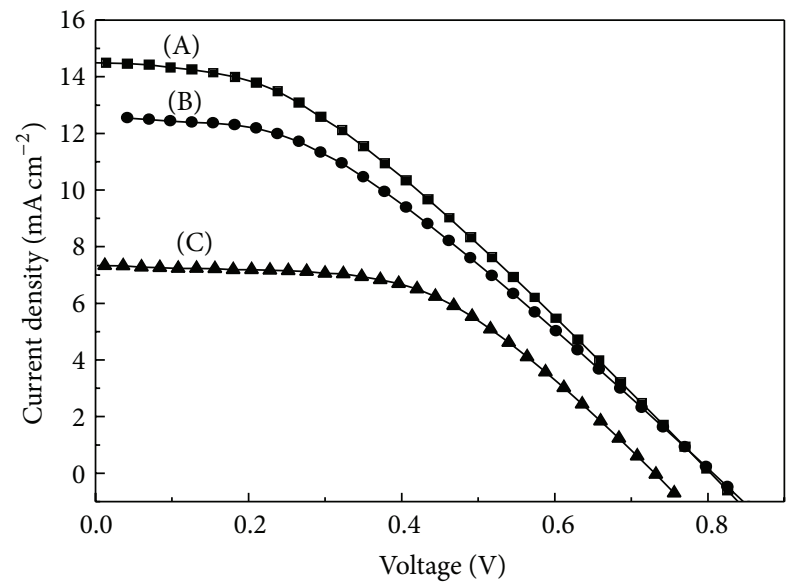

(d)

Figure 3: Cross section of SEM images of $\mathrm{TiO}_{2}$ P25 layers with thicknesses of (a) 8, (b) 10, and (c) $12 \mu \mathrm{m}$. (d) It is the corresponding $I$ - $V$ curves.

of the redox species between the counter and working electrodes, which is well described by the Nernst diffusion impedance [27]:

$$
W_{s}=Z_{\text {diffusion }}=\frac{R_{d}}{\sqrt{j \omega}} \tanh \left(\sqrt{\frac{j \omega}{\omega_{d}}}\right),
$$

where $R_{d}$ is the diffusion resistance and the angular frequency is $\omega$. The characteristic frequency $\omega_{d}$ is given by $\omega_{d}=D / L_{0}{ }^{2}$ and the characteristic time of ion diffusion is $\tau_{d}=1 / \omega_{d}$, where $D$ is the diffusion coefficient of species of electrolyte and $L_{0}$ is the effective thickness of the cell, and the diffusion resistance is in the low frequency region of the impedance spectra [29].
In Nyquist plot (Figure 6(a)), the impedance arcs of DSSCs decreased gradually with increasing spacer thickness, from $30 \mu \mathrm{m}$ to $50 \mu \mathrm{m}$. From the EIS calculations, using the fitting program ( $Z$ view), we could conclude that, with small amount of electrolyte, there was high value of internal resistance, which consisted of transport resistance $\left(R_{p}\right)$ and transfer resistance $\left(R_{f}\right)$. Larger amount of electrolyte gave smaller impedance arc diameter.

The impedance spectra were fitted to a geometrically appropriate equivalent circuit, as shown in Figure 6(b). The transport resistance $R_{p}$ and charge transfer from recombination process $R_{f}$ are following exponential behavior, in which the increase of concentration of charges lowers the measured resistances $[30,31]$. The data in Table 4 represent that 
TABLE 4: EIS parameters of DSSCs with different spacer thicknesses.

\begin{tabular}{|c|c|c|c|c|c|c|c|c|c|c|c|}
\hline DSSC & $R_{s}(\Omega)$ & $R_{p}(\Omega)$ & $C_{p}(\mu \mathrm{F})$ & $R_{f}(\Omega)$ & $C_{f}(\mu \mathrm{F})$ & $R_{\mathrm{Pt} / \text { lect }}(\Omega)$ & $C_{\mathrm{Pt} / \text { elect }}(\mu \mathrm{F})$ & $W_{s}(\Omega)$ & $d(\mu \mathrm{m})$ & $\tau_{n}(\mathrm{~ms})$ & $\tau(\mathrm{ms})$ \\
\hline $30 \mu \mathrm{m}$ & 13.2 & $783 \pm 39$ & $9.6 \pm 0.3$ & $4228 \pm 64$ & $9.9 \pm 0.1$ & 1.24 & 0.66 & $802 \pm 107$ & 23.0 & 41.9 & 7.75 \\
\hline $40 \mu \mathrm{m}$ & 8.17 & $533 \pm 20$ & $16.8 \pm 0.8$ & $1075 \pm 30$ & $10.4 \pm 0.1$ & 1.74 & 0.23 & $319 \pm 109$ & 14.2 & 11.2 & 5.55 \\
\hline $50 \mu \mathrm{m}$ & 8.1 & $212 \pm 11$ & $45.0 \pm 0.3$ & $577 \pm 32$ & $10.8 \pm 0.4$ & 1.29 & 0.35 & $3303 \pm 528$ & 16.4 & 6.3 & 2.31 \\
\hline
\end{tabular}

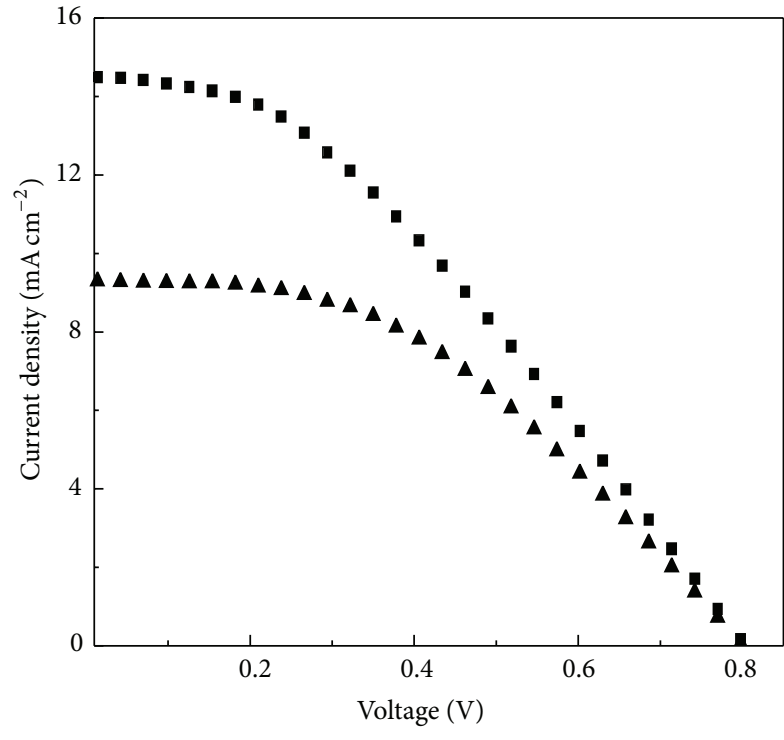

- $6 \times 10^{-3} \mathrm{~mL}$

A $3 \times 10^{-3} \mathrm{~mL}$

FIGURE 4: $I-V$ curves of two DSSC samples have different amount of electrolyte solution.

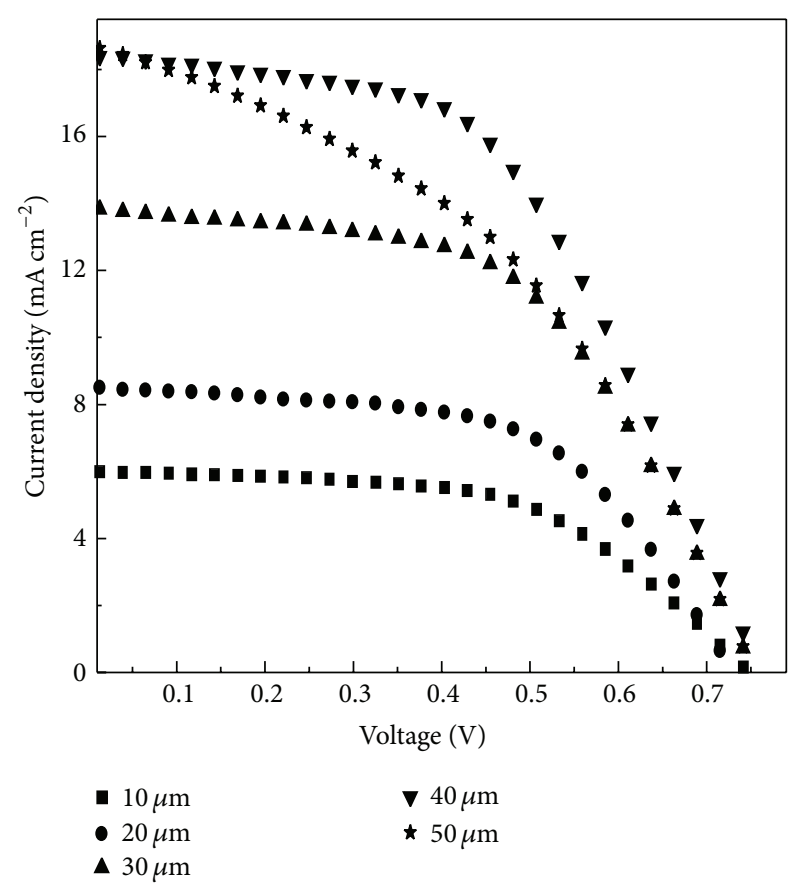

FIGURE 5: $I-V$ curves of DSSC samples with different spacer thicknesses: 10, 20, 30, 40, and $50 \mu \mathrm{m}$. the values of $R_{p}, R_{f}$, and $\tau_{n}$ decrease with increasing spacer thicknesses indicating increasing the rate of recombination. Consequently, transport and recombination resistances affect the concentration of electrons in the film. The diffusion length, $d$, is defined by the charge-transfer resistance for recombination and transport resistance by the efficiency, by which the injected electrons are collected at the conducting substrate $\left(d=\ell \times \sqrt{R_{f} / R_{p}}\right.$ [32]). To achieve high chargecarrier collection efficiency, the diffusion length needs to be larger than the film thickness, $d>\ell$. The diffusion length for our DSSCs was found to be excellent because their values are higher than the $\mathrm{TiO}_{2}$ film thickness $(\ell=8 \mu \mathrm{m})$. The second charge-transfer process which would normally be detected is the charge-transfer process at the counter electrode, which is related to the reduction of the redox couple in the electrolyte, $R_{\mathrm{Pt}}$, increasing with an increase in the flux of electrons at the counter electrode [31]. Because the cross section area (area of active layer $1 \mathrm{~cm} \times 1 \mathrm{~cm}$ ) and sputtered Platinum thickness $(100 \mathrm{~nm})$ are the same for all samples, the data of $R_{\mathrm{Pt}}$ and $C_{\mathrm{Pt}}$ have no distinct changes.

The electron lifetime $\left(\tau_{e}\right)$ in the P25 layer can be calculated as follows [32]:

$$
\tau_{e}=R_{f} \times C_{f} ;
$$

the time constant for the transfer of electrons from the electrolyte to the P25 layer decreased with increasing spacer thickness. This behavior may thus explain the decrease in fill factor in spite of the increase of photocurrent density inside the P25 layer. In simulation process, the electron transit time $(t)$, through the P25 layer, could be obtained by the following equation [33]:

$$
\frac{t}{\tau_{e}}=\frac{R_{p}}{R_{f}} ;
$$

comparing with other groups using experimental technique like the open-circuit voltage decay (OCVD) [4, 23], the calculated time constants are approximately in the same order. It is interesting to note that the cell containing spacer thickness of $30 \mu \mathrm{m}$ gives the highest lifetime $\left(\tau_{e}\right)$ value as seen in Table 4. This result can be attributed to the slower of both the recapture of conduction band electrons by $\mathrm{I}_{3}{ }^{-}$ions and the recombination process. On the other hand, it was found that, at using $40 \mu \mathrm{m}$ spacer thicknesses, the highest efficiency value has been obtained which is in good agreement with minimum value of Warburg resistance.

According to the fitted data in Table 4, as spacer thickness increases, the internal resistance and electron lifetime decrease. This behavior points to no gradual change of 


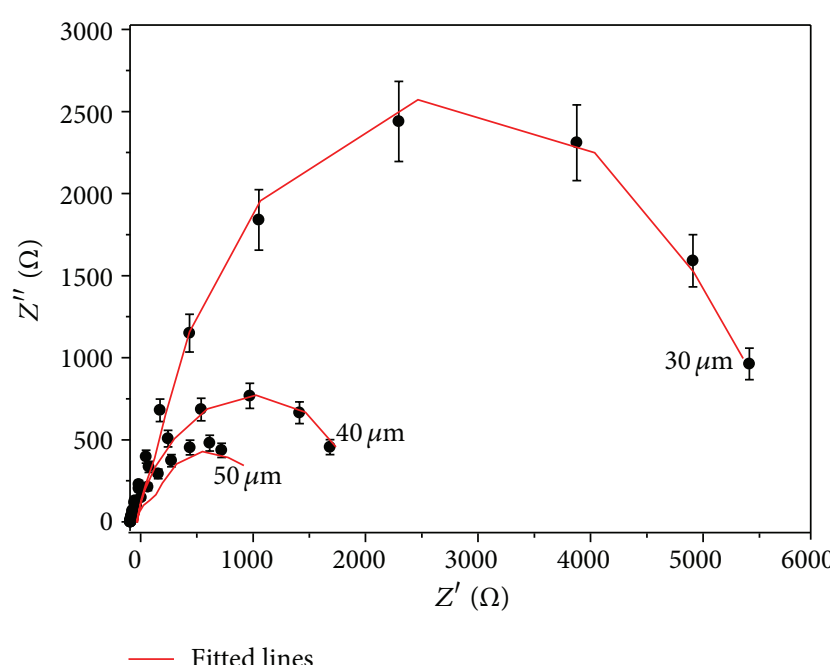

(a)

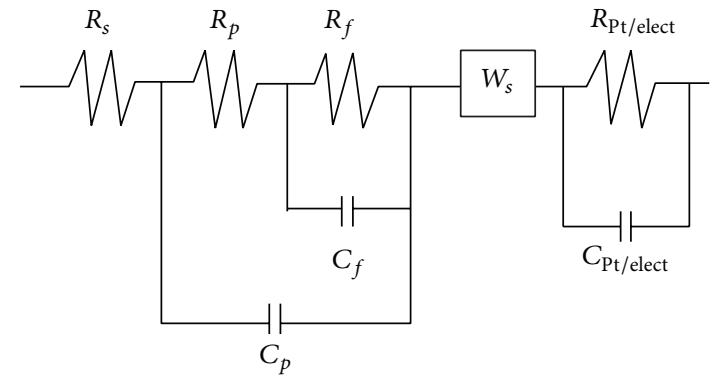

(b)

FIGURE 6: (a) Nyquist plots of three DSSC samples with 30, 40, and $50 \mu \mathrm{m}$ spacer thicknesses with error bar 10\%. The red solid lines represent the fitting curves of the corresponding equivalent circuit in (b).

cell parameters. The decrease of internal resistance led to improvement of the cell parameters, while the decrease of lifetime rising of the recombination process $[33,34]$ resulting in deteriorates the cell parameters. So, there is a competition between the effect of internal resistance and lifetime changes.

In addition, there is another competition inside electrolyte solution between diffusion coefficient of the oxidant and/or reluctant and number of electrons involved; all these parameters increase with increasing amount of electrolyte and represent a minimum value of Warburg resistance and maximum value of the cell efficiency, and therefore these conditions agree at optimum spacer thickness at $40 \mu \mathrm{m}$. In this case, the effective deciding factors were the electrolyte Warburg resistance, internal resistance, and electron lifetime.

\section{Conclusion}

This study has helped in enhancement of DSSCs efficiency from about $3.2 \%$ to high value $7.2 \%$, with optimum conditions of P25 layer thickness, spacer thickness, and amount of electrolyte. An optimum thickness of $8 \mu \mathrm{m}$ was obtained for the P25 layer. The efficiency increased with increasing spacer thickness, obtaining an optimum thickness of $40 \mu \mathrm{m}$. From EIS measurements, the highest efficiency of $7.2 \%$ was achieved at the lower value of Warburg resistance corresponding to the amount of electrolyte using the optimum spacer thickness of $40 \mu \mathrm{m}$.

\section{Conflict of Interests}

The authors declare that there is no conflict of interests regarding the publication of this paper.

\section{Acknowledgments}

The authors wish to express their gratefulness to the Egyptian government for the scholarship to Japan. The authors would also like to thank Mr. Teruhisa Okuno and Mr. Pascal Nbelayin, who assisted in doing all experiments. This work was financially supported by Tatematsu Foundation.

\section{References}

[1] B. O’Regan and M. Grätzel, "A low-cost, high-efficiency solar cell based on dye-sensitized colloidal TiO2 films," Nature, vol. 353, no. 6346, pp. 737-740, 1991.

[2] S. Yang, H. Kou, H. Wang, K. Cheng, and J. Wang, “The photoelectrochemical properties of $\mathrm{N} 3$ sensitized $\mathrm{CaTiO}_{3}$ modified $\mathrm{TiO}_{2}$ nanocrystalline electrodes," Electrochimica Acta, vol. 55, no. 1, pp. 305-310, 2009.

[3] J. Gong, J. Liang, and K. Sumathy, "Review on dye-sensitized solar cells (DSSCs): fundamental concepts and novel materials," Renewable and Sustainable Energy Reviews, vol. 16, no. 8, pp. 5848-5860, 2012.

[4] M. Pan, N. Huang, X. Zhao, J. Fu, and X. Zhong, "Enhanced efficiency of dye-sensitized solar cell by high surface area anatase- $\mathrm{TiO}_{2}$-modified P25 paste," Journal of Nanomaterials, vol. 2013, Article ID 760685, 6 pages, 2013.

[5] Y. Wang, E. Chen, H. Lai et al., "Enhanced light scattering and photovoltaic performance for dye-sensitized solar cells by embedding submicron $\mathrm{SiO}_{2} / \mathrm{TiO}_{2}$ core/shell particles in photoanode," Ceramics International, vol. 39 , no. 5, pp. 54075413, 2013.

[6] C.-S. Chou, M.-G. Guo, K.-H. Liu, and Y.-S. Chen, "Preparation of $\mathrm{TiO}_{2}$ particles and their applications in the light scattering layer of a dye-sensitized solar cell," Applied Energy, vol. 92, pp. 224-233, 2012.

[7] S. H. Kang, J.-Y. Kim, H. S. Kim, H.-D. Koh, J.-S. Lee, and Y.-E. Sung, "Influence of light scattering particles in the $\mathrm{TiO}_{2}$ photoelectrode for solid-state dye-sensitized solar cell," Journal of Photochemistry and Photobiology A: Chemistry, vol. 200, no. 2-3, pp. 294-300, 2008.

[8] S. C. Choi, H. S. Lee, and S. H. Sohn, "Effects of light scattering $\mathrm{TiO}_{2}$ surface-modified by dual oxide coating in dye-sensitized 
solar cells," Advanced Powder Technology, vol. 23, no. 6, pp. 866871, 2012.

[9] H. Lai, Y. Wang, G. Du, W. Li, and W. Han, "Dual functional $\mathrm{YVO}_{4}: \mathrm{Eu}^{3+}, \mathrm{Bi3}^{+} @ \mathrm{SiO}_{2}$ submicron-sized core-shell particles for dye-sensitized solar cells: light scattering and downconversion," Ceramics International, vol. 40, no. 4, pp. 6103-6108, 2014.

[10] L. Zhu, Y. L. Zhao, X. P. Lin, X. Q. Gu, and Y. H. Qiang, "The effect of light-scattering layer on the performance of dyesensitized solar cell assembled using $\mathrm{TiO}_{2}$ double-layered films as photoanodes," Superlattices and Microstructures, vol. 65, pp. 152-160, 2014.

[11] J. S. Lee, K. H. Kim, C. S. Kim, and H. W. Choi, "Achieving enhanced dye-sensitized solar cell performance by $\mathrm{TiCl}_{4} / \mathrm{Al}_{2} \mathrm{O}_{3}$ doped $\mathrm{TiO}_{2}$ nanotube array photoelectrodes," Journal of Nanomaterials, vol. 2015, Article ID 545818, 6 pages, 2015.

[12] W. Zhao, H. Bala, J. Chen et al., “Thickness-dependent electron transport performance of mesoporous $\mathrm{TiO}_{2}$ thin film for dyesensitized solar cells," Electrochimica Acta, vol. 114, pp. 318-324, 2013.

[13] A. Yella, H.-W. Lee, H. N. Tsao et al., "Porphyrin-sensitized solar cells with cobalt (II/III) - based redox electrolyte exceed 12 percent efficiency," Science, vol. 334, no. 6056, pp. 629-633, 2011.

[14] M.-J. Kim, Y.-J. Yu, J.-H. Kim et al., “Tuning of spacer groups in organic dyes for efficient inhibition of charge recombination in dye-sensitized solar cells," Dyes and Pigments, vol. 95, no. 1, pp. 134-141, 2012.

[15] K.-M. Lee, C.-Y. Hsu, W.-H. Chiu et al., "Dye-sensitized solar cells with a micro-porous $\mathrm{TiO}_{2}$ electrode and gel polymer electrolytes prepared by in situ cross-link reaction," Solar Energy Materials and Solar Cells, vol. 93, no. 11, pp. 2003-2007, 2009.

[16] S. Ganesan, B. Muthuraaman, V. Mathew, J. Madhavan, P. Maruthamuthu, and S. A. Suthanthiraraj, "Performance of a new polymer electrolyte incorporated with diphenylamine in nanocrystalline dye-sensitized solar cell," Solar Energy Materials \& Solar Cells, vol. 92, no. 12, pp. 1718-1722, 2008.

[17] S. Anandan, "Recent improvements and arising challenges in dye-sensitized solar cells," Solar Energy Materials \& Solar Cells, vol. 91, no. 9, pp. 843-846, 2007.

[18] K. Imoto, K. Takahashi, T. Yamaguchi, T. Komura, J.-I. Nakamura, and K. Murata, "High-performance carbon counter electrode for dye-sensitized solar cells," Solar Energy Materials and Solar Cells, vol. 79, no. 4, pp. 459-469, 2003.

[19] F. P. Koffyberg and F. A. Benko, "A photoelectrochemical determination of the position of the conduction and valence band edges of p-type CuO," Journal of Applied Physics, vol. 53, no. 2, pp. 1173-1177, 1982.

[20] B. Lee, D. B. Buchholz, and R. P. H. Chang, "An all carbon counter electrode for dye sensitized solar cells," Energy and Environmental Science, vol. 5, no. 5, pp. 6941-6952, 2012.

[21] S. Anandan, X. G. Wen, and S. H. Yang, "Room temperature growth of $\mathrm{CuO}$ nanorod arrays on copper and their application as a cathode in dye-sensitized solar cells," Materials Chemistry and Physics, vol. 93, no. 1, pp. 35-40, 2005.

[22] M. T. Zanni, B. J. Greenblatt, A. V. Davis, and D. M. Neumark, "Photodissociation of gas phase using femtosecond photoelectron spectroscopy," Journal of Chemical Physics, vol. 111, pp. 2991-2003, 1999.

[23] J. Bisquert, A. Zaban, M. Greenshtein, and I. Mora-Seró, "Determination of rate constants for charge transfer and the distribution of semiconductor and electrolyte electronic energy levels in dye-sensitized solar cells by open-circuit photovoltage decay method," Journal of the American Chemical Society, vol. 126, no. 41, pp. 13550-13559, 2004.

[24] M. Filipič, M. Berginc, F. Smole, and M. Topič, "Analysis of electron recombination in dye-sensitized solar cell," Current Applied Physics, vol. 12, no. 1, pp. 238-246, 2012.

[25] C. Legrand-Buscema, C. Malibert, and S. Bach, "Elaboration and characterization of thin films of $\mathrm{TiO}_{2}$ prepared by sol-gel process," Thin Solid Films, vol. 418, no. 2, pp. 79-84, 2002.

[26] A. Luque and A. Martí, "Increasing the efficiency of ideal solar cells by photon induced transitions at intermediate levels," Physical Review Letters, vol. 78, no. 26, pp. 5014-5017, 1997.

[27] Q. Wang, J.-E. Moser, and M. Grätzel, "Electrochemical impedance spectroscopic analysis of dye-sensitized solar cells," Journal of Physical Chemistry B, vol. 109, no. 31, pp. 14945-14953, 2005.

[28] S.-C. Yang, D.-J. Yang, J. Kim et al., "Hollow $\mathrm{TiO}_{2}$ hemispheres obtained by colloidal templating for application in dyesensitized solar cells," Advanced Materials, vol. 20, no. 5, pp. 1059-1064, 2008.

[29] F. Fabregat-Santiago, J. Bisquert, E. Palomares et al., "Correlation between photovoltaic performance and impedance spectroscopy of dye-sensitized solar cells based on ionic liquids," The Journal of Physical Chemistry C, vol. 111, no. 17, pp. 6550-6560, 2007.

[30] F. Fabregat-Santiago, J. Bisquert, G. Garcia-Belmonte, G. Boschloo, and A. Hagfeldt, "Influence of electrolyte in transport and recombination in dye-sensitized solar cells studied by impedance spectroscopy," Solar Energy Materials and Solar Cells, vol. 87, no. 1-4, pp. 117-131, 2005.

[31] Q. Wang, S. Ito, M. Grätzel et al., "Characteristics of high efficiency dye-sensitized solar cells," The Journal of Physical Chemistry B, vol. 110, no. 50, pp. 25210-25221, 2006.

[32] J. Maçaira, L. Andrade, and A. Mendes, "Review on nanostructured photoelectrodes for next generation dye-sensitized solar cells," Renewable \& Sustainable Energy Reviews, vol. 27, pp. 334349, 2013.

[33] A. M. Bakhshayesh, M. R. Mohammadi, and D. J. Fray, "Controlling electron transport rate and recombination process of $\mathrm{TiO}_{2}$ dye-sensitized solar cells by design of double-layer films with different arrangement modes," Electrochimica Acta, vol. 78, pp. 384-391, 2012.

[34] M. Li, Y. Liu, H. Wang, and H. Shen, "Synthesis of $\mathrm{TiO}_{2}$ submicro-rings and their application in dye-sensitized solar cell," Applied Energy, vol. 88, no. 3, pp. 825-830, 2011. 

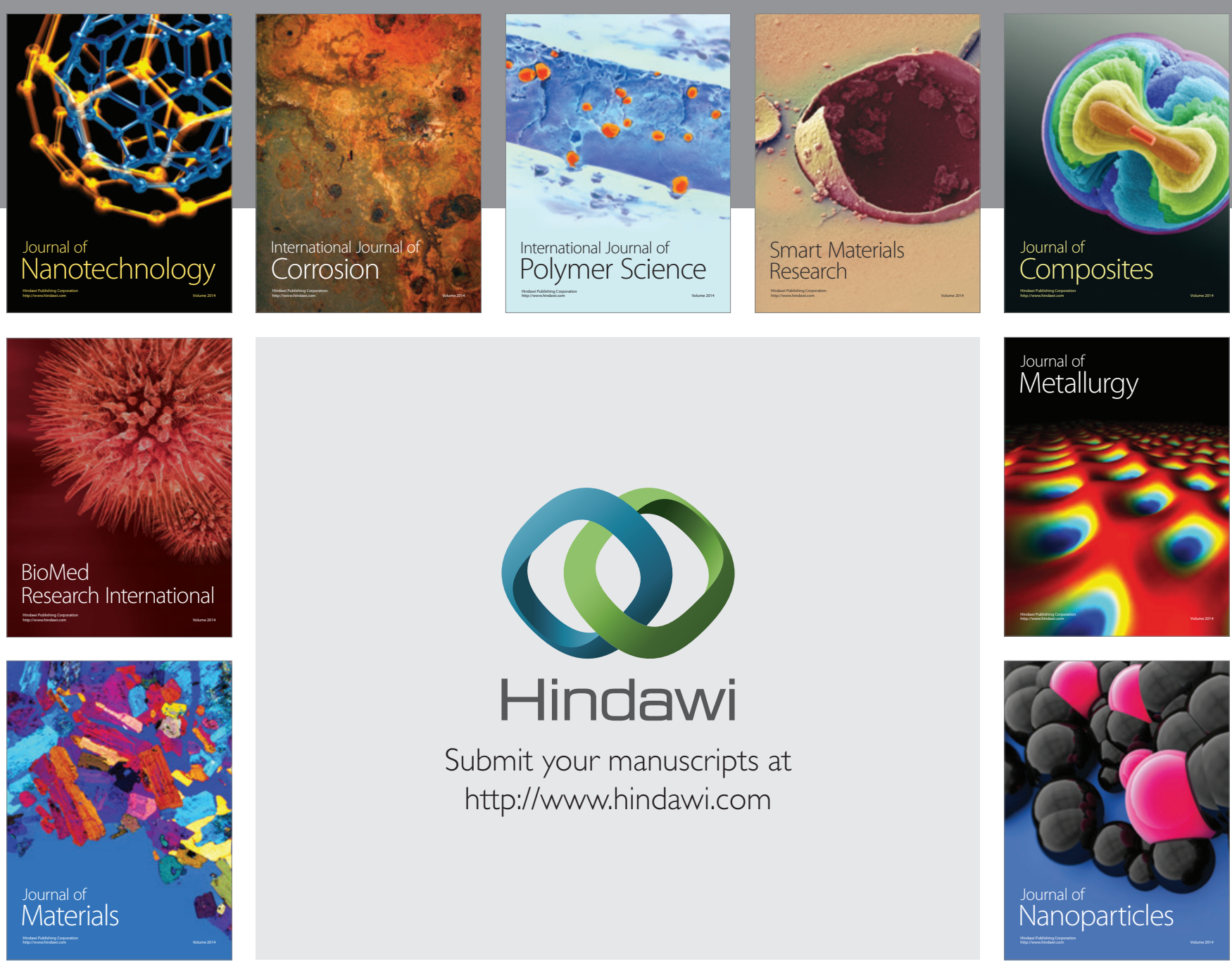

Submit your manuscripts at http://www.hindawi.com
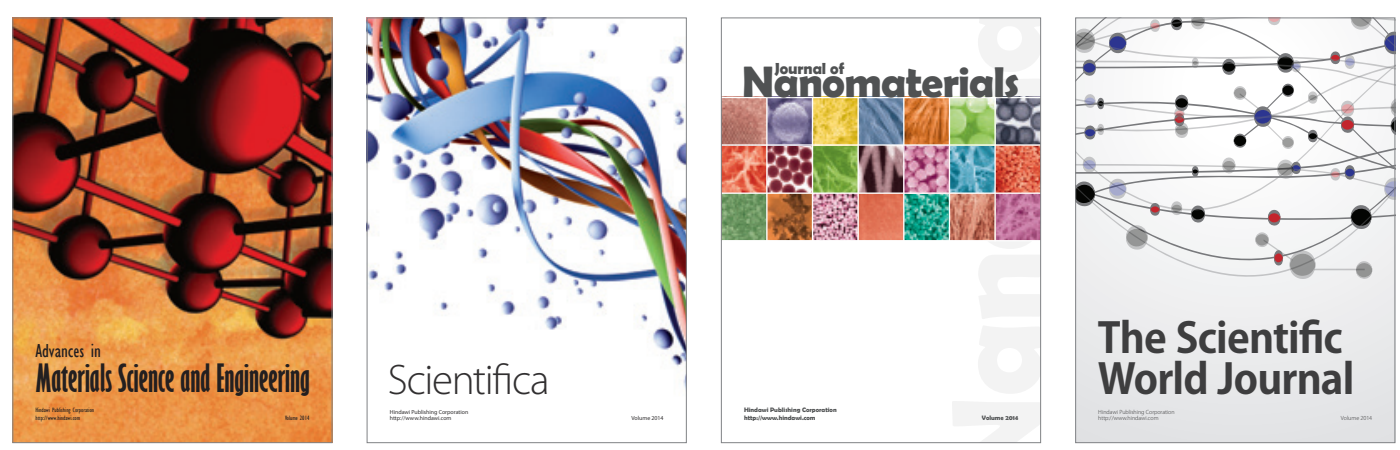

\section{The Scientific World Journal}
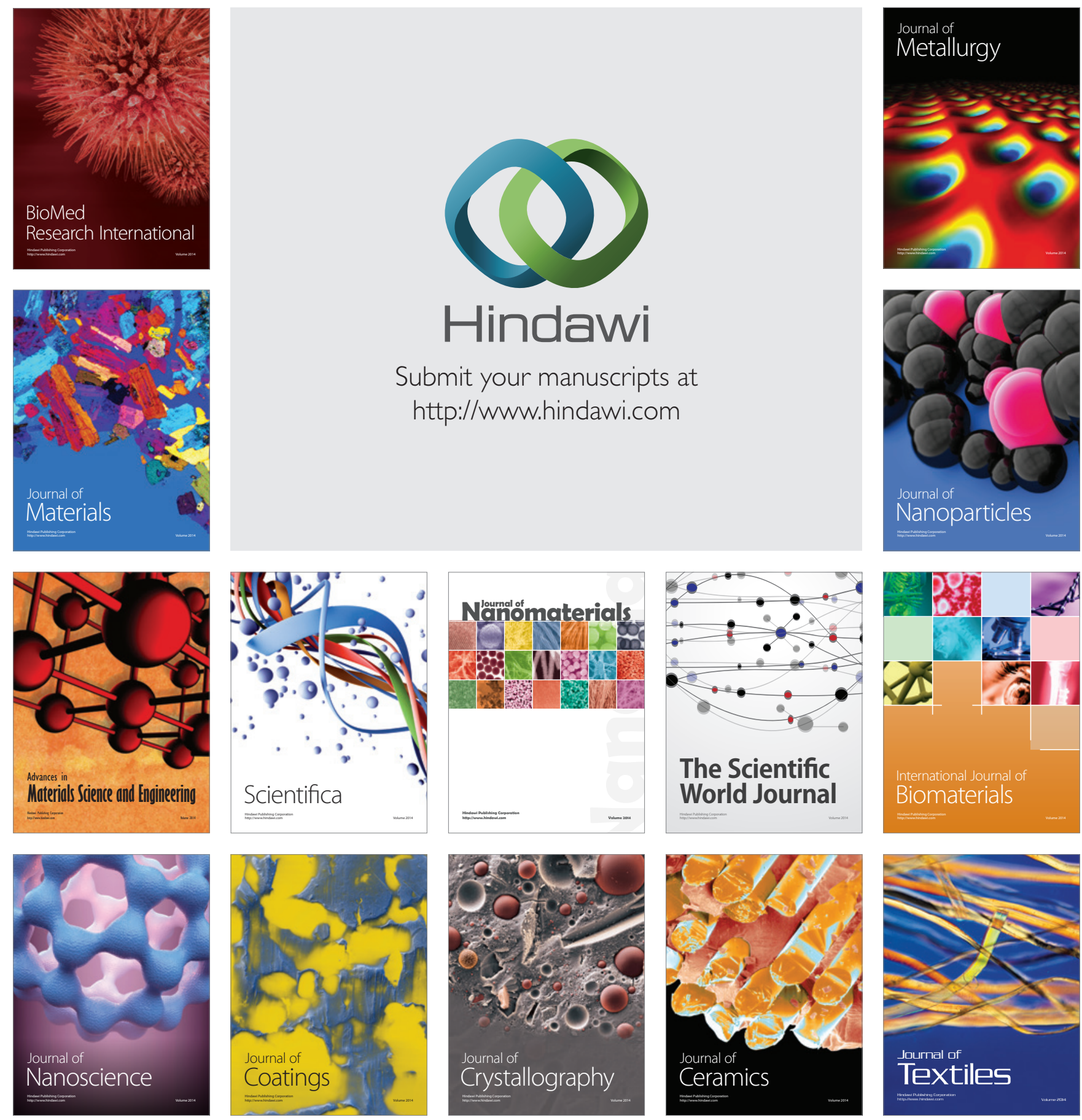